\title{
DESCRIPTIONS OF EIGHTEEN NEW SPECIES OF FISHES FROM THE WILKES EXPLORING EXPE- DITION, PRESERVED IN THE UNITED STATES NATIONAL MUSEUM.
}

\author{
By Henry W. Fowler. \\ of the Academy of Natural Sciences of Philadelphia, \\ AND \\ Barton A. Bean, \\ of the United States National Museum.
}

In the preparation of a report upon the fishes collected by the Wilkes Exploring Expedition around the world, the following are described as new :

Harengula peruana, new species, from Callao, Peru.

Wilkesina, new subgenus.

Harengula fijiense, new species, from Fiji.

Anchoviella mauii, new species, from Maui, Hawaiian Islands.

Anchoviella salvatoris, new species, from Rio Janeiro, Brazil.

Rasborella, new genus.

Rasborella dubia, new species, from Indo-Malayan region?

Uropterygius fijiensis, new species, from Fiji.

Hyporhamphus salvatoris, new species, from Rio Janeiro, Brazil. Strongylura tahitiensis, new species, from Tahiti.

Strongylura auloceps, new species, from Fiji or Samoa.

Strongylura fijiense, new species, from Fiji.

Lepthaemulon, new subgenus.

Orthopristis rhabdotus, new species, from Peru?

Ctenosciaena, new subgenus.

Sciaena dubia, new species (no locality).

Paralarimus, new genus.

Paralarimus patagonicus, new species, from northern Patagonia. Lepidaplois trotteri, new species, from Pomotou Islands.

Chromis cupreus, new species, from "Singapore, Maui, or Samoa." Gillellus australis, new species, from Valparaiso, Chile.

Salarias mccullochi, new species, from Billinghausen Island.

Xystreurys ribeiroi, new species, from Rio Janeiro, Brazil.

No. 2488-Proceedings U. S. National Museum, Vol. 63, Art. 19.

5596-24-Proc.N.M.vol.63-34 
HARENGULA PERUANA, new species.

Head $3 \frac{3}{5}$; depth $3 \frac{1}{6}$; D. iv, 14 ; A. ii, 14 ?; P. i, 14; V. i, 7; scales 37 in median lateral series to caudal base and 4 more on latter; 10 scales transversely at dorsal origin; 13 predorsal scales; head width 2 in its length; head depth $1 \frac{1}{8}$; mandible $2 \frac{1}{8}$; dorsal base $1 \frac{3}{5}$; anal base $1 \frac{3}{4}$; least depth of caudal peduncle $2 \frac{2}{3}$; pectoral $1 \frac{1}{2}$; ventral $2 \frac{1}{2}$ ?; snout 4 in head, measured from upper jaw tip; eye $3 \frac{1}{2}$; maxillary $2 \frac{1}{8}$; interorbital $4 \frac{1}{2}$; serrae $17 ?+15$ ? (damaged).

Body well compressed, deepest at dorsal origin, contour rather ovoid, and upper edge little trenchant. Abdominal serrae distinct, edges slightly exposed. Caudal peduncle well compressed, about as long as deep.

Head large, strongly compressed, lower profile slightly more inclined, flattened sides converging below. Snout short, width $1 \frac{1}{4}$ its length; eye moderate, circular, hind pupil edge nearly midway in head length. Adipose eyelid moderately developed. Mouth small, terminally superior or lower jaw protruding and upper with slight median notch, short gape scarcely evident. Maxillary to eye center, about $\frac{3}{4}$ covered by preorbital; expansion $1 \frac{4}{5}$ in eye. Front of jaws each with rather regular single row of few moderately small simple teeth. No vomerine teeth, but broad band of fine numerous teeth on each pterygoid. 'Tongue free, pointed, covered with similar fine teeth, also in broad patch. Mandibular rami greatly elevated on each side within mouth; each slips in cavity outside of each palatine. Nostrils little nearer snout tip than eye. Interorbital with low median ridge in front and 3 closely set supercilliary ridges on each side. Cheek, opercle, and preopercle with rather obscure striae.

Gill-opening forward to front eye edge. Gill-rakers about $18+36$, slenderly lanceolate, a little longer than filaments or about $1 \frac{1}{2}$ in eye. Pseudobranchiae about long as filaments. Isthmus narrow slender frenum. Shoulder girdle inside gill opening with notch over pectoral origin.

Scales firmly adherent, all narrowly imbricated, largest along middle of sides and those on predorsal anteriorly with more frayed or gashed edges than others, often with about a dozen marginal lines. Circuli as very fine vertical parallel striae, and each scale also with two larger well-spaced vertical prominent striae. Dorsal and anal with broad basal sheaths of small scales; caudal base covered with moderately large scales, though smaller than those on body. Ventral with scaly flap about two-thirds length of fin. Humeral adipose area scarcely developed.

Dorsal origin nearer mandible tip than caudal base by a space equal to combined snout and eye lengths. Anal origin slightly liearer caudal base than ventral origin, fin low and largely concealed in basal sheath. Caudal damaged. Pectoral about four-fifths (tip 
damaged) to ventral, or slightly beyond dorsal origin. Ventral inserted nearly midway between mandible tip and last anal ray base, about one-third (tip damaged) to anal.

Color in alcohol with back above dull olivaceous. Sides, iris, and lower surface pale brassy. Fins all pale.

Length $105 \mathrm{~mm}$. (caudal tips damaged).

Type.-No. 83156, U.S.N.M., from Callao, Peru, Wilkes Exploring Expedition. Only the type known. This species is closely allied with Clupea thrissina Jordan and Gilbert, but that is described with a dark humeral spot, certainly not evident in our example.

(Named for Peru.)

WILKESINA, new subgenus.

Type.-Harengula fijiense, new species.

Distinguished from subgenus Harengula by the very numerous and fine gill-rakes, which are 70 on the lower arch.

Harengula nymphaea Richardson from China and the species described below form this group.

(For Admiral Charles Wilkes, U. S. N., the distinguished commander of the U. S. Exploring Expedition 1839-1842.)

HARENGULA FIJIENSE, new species.

Head, $3 \frac{1}{5}$; depth, $3 \frac{2}{5}$; D. iv. 13,1 ; A. ii, 17 ; P. i, 14 ; V. i, 7 ; scales, 39 in median lateral series to caudal base and 3 more on latter; 11 scales transversely at dorsal origin; 16 predorsal scales; head width, 22 in its length; head depth, $1 \frac{2}{5}$; length of depressed dorsal, $1 \frac{2}{5}$; length of depressed anal, $1 \frac{3}{4}$; least depth of caudal peduncle, $2 \frac{4}{5}$; snout 4 in head from upper jaw tip; eye, $3 \frac{1}{6}$; maxillary, $2 \frac{1}{4}$; interorbital, $4 \frac{1}{5}$; serrae, $14+12$.

Body well compressed, with ellipsoid contour, deepest about ventral origin, and edges trenchant. Caudal peduncle well compressed, length about three-fourths its least depth.

Head moderate, compressed, profile pointed, flattened, sides convergent below. Snout long as wide. Eye long as snout, advanced or hind pupil edge about midway in head length. Adipose eyelid moderate. Mouth small, lower jaw protruding and rami well elevated inside of mouth. Maxillary reaches first third in eye; expansion $1 \frac{1}{2}$ in eye. No teeth. Nostril about midway in snout length. Interorbital level. Opercle smooth, only obsolete short impressions of radiating striae. Cheeks with more distinct lines radiating or sloping forward.

Gill-opening extends forward opposite front eye edge. Gillrakers about $50+70$, finely lanceolate, longer than filaments or $\frac{3}{4}$ of eye. Pseudobranchiae long as or little longer than gill-filaments. 
Isthmus long slender frenum. Shoulder girdle inside gill-opening with notch below.

Scales firmly adherent, in even longitudinal rows, narrowly imbricated, and low sheath along dorsal base. Ventrals with pointed axillary flap at least two-fifths fin length. Caudal base scaled. Scales with 4 parallel vertical striae, also very numerous finer or less distinct parallel striae.

Dorsal inserted nearly midway between mandible tip and base of last anal ray, fin $2 \frac{1}{2}$ to caudal base. Anal inserted well behind dorsal or about midway between ventral origin and caudal base, fin low, caudal (damaged) apparently emarginate. Pectoral (damaged) reaches at least three-fifths to ventral. Ventral inserted little behind dorsal origin and not quite reaching halfway to anal. Vent close in front of anal.

Color in alcohol: Back dark bluish-brown, sides and below silvery white with brassy tinge. Iris pale or brownish-yellow. Fins pale brownish, tip of dorsal dusky.

Length $73 \mathrm{~mm}$. (caudal tips damaged).

Type.-Cat. No. 82799. U.S.N.M., Fiji Island, Wilkes Exploring Expedition. Another example, paratype, with same data, showing: Head $3 \frac{1}{3}$; depth $3 \frac{3}{5}$; D. iv, 13,1 ; A. ii, 16 ; scales 39 in lateral series to caudal base and 4 more on latter; snout $3 \frac{1}{4}$ in head from upper jaw tip ; eye $3 \frac{1}{4}$; maxillary $2 \frac{1}{6}$; interorbital $4 \frac{1}{5}$; serrae $17+13$. Length 64 mm. (caudal damaged).

The above examples differ from the other species of the genus in Polynesia in the dark tip to the dorsal.

(Named for the Fiji Islands.)

ANCHOVIELLA MAUII, new species.

Head 3 ; depth (at head) 5; D. iii, 12; A. iii, 11?; P. i, 13; V. i, 6; scales (impressions estimated) about 40 to caudal base; about 20 predorsal scales. Snout $4 \frac{3}{5}$ in head; eye 4 ; maxillary $1 \frac{1}{8}$; interorbital $6 \frac{1}{5}$; least depth of caudal peduncle $3 \frac{1}{2}$; head width $3 \frac{1}{8}$.

Body moderately long, well compressed, apparently deepest at gill opening, ventral edge rounded convexly and without scutes. Caudal peduncle compressed, least depth $1 \frac{1}{2}$ its length.

Head long, well compressed, pointed, flattened sides but slightly converging below snout conic, width $1 \frac{1}{6}$ its length and lower profile slightly concave. Eye large, hind pupil edge about first third in head. Adipose eyelid covers eye. Mouth large. Mandible extends forward little before front eye edge, though not quite to nostril, rami low. Maxillary long, straight, extends back little beyond mandibular articulation or preopercle ridge, though not quite to gill-opening. Maxillary and upper jaw edges in front with row of minute closeset simple teeth. Row along mandibular edge similar, except larger on lateral extent. Several very minute teeth as short row on front 
of each palatin but none on vomer. Tongue small knob in front of lower jaw. Nostril small pore about midway in snout. Interorbital moderate, scarcely elevated or with distinct median ridge and each superciliary giving off keel behind approximating nape. Cheeks long, isosceles triangle with basal width about half its length. Cheeks and opercle smooth.

Gill-opening extends forward about midway in space between front pupil edge and front eye edge. Gill-rakers about $35+40$, finely lanceolate, longest much longer than filaments or about equal eye. Pseudobranchiae about half length of filaments. Isthmus long, slender frenum.

Scales caducous, few still adherent, with about 5 basal and as many transverse incomplete striae, all apparently narrowly imbricate. Dorsal and anal within scaly basal sheaths.

Dorsal origin about midway between front eye edge and caudal base. Anal inserted close behind dorsal base. Pectoral small (damaged) and not reaching much over $\frac{2}{5}$ ? to ventral. Latter also small and inserted close before dorsal origin, fin (damaged) about $\frac{1}{3}$ ? to anal. Vent close before anal. Color in alcohol, skin dull olive generally, sides with median broad lateral silvery sheen, better defined after anal, where it is about as wide as eye. Head, including iris, silvery-white.

Length $75 \mathrm{~mm}$. (caudal damaged).

Type.-Cat. No. 82,904, U.S.N.M. From Maui, Hawaiian Islands. Another example, same data, paratype, shows: Head about 3 ; depth at head $5 \frac{1}{2}$; D. iii, 12 ; snout $5 \frac{1}{6}$ in head; eye $4 \frac{1}{6}$; maxillary $1 \frac{1}{5}$ interorbital 6. Gill-rakers $37+44$; length $77 \mathrm{~mm}$. (caudal damaged).

Though very close to Engraulis ringens, this species may be distinguished by its longer maxillary. Comparison was made with the only other member of the family from Hawaiian waters, Anchoviella purpurea (Fowler). Of this species, besides the types, nine others in the Academy show: Head $3 \frac{1}{3}$ to $3 \frac{3}{4}$; depth 5 to $5 \frac{3}{4}$; D. iii, 12, 1 , branched rays sometimes 11 , rarely $10 ; \mathrm{A}$. iii, 14,1 , branched rays seldom 15 ; scales usually 38 to caudal base, sometimes 39,40 , or 41 ; 9 or 10 scales transversely between dorsal origin and middle of belly; usually 20 predorsal scales, sometimes 19 or 21 ; snout 4 to 5 in head; eye $3 \frac{1}{3}$ to 4 ; maxillary $1 \frac{1}{5}$ to $1 \frac{2}{5}$; interorbital $4 \frac{1}{4}$ to $4 \frac{3}{4}$. Body well compressed, belly rounded. Maxillary not quite to mandible joint, toothed. Gill-opening forward to eye front. Gill-rakers $21+21$, fine, $1 \frac{1}{5}$ in eye. Scaly axillary pectoral flap $1 \frac{1}{2}$ in fin. Dorsal origin midway between eye front and caudal base. Anal inserted immediately after dorsal base. Pectoral two-thirds to ventral. Caudal forked, lobes about equal, pointed. Broad silverywhite lateral band wide as eye. Length 80 to $89 \mathrm{~mm}$.

(For Maui, the type locality.) 
ANCHOVIELLA SALVATORIS, new species.

Head, $3 \frac{3}{4}$; depth, 5; D. iii, 10; A. iii, 14?; P. i, 13; V. i, 6; scales (pockets) 38? in median lateral series to caudal base; 9 ? scales (pockets) transversely at dorsal origin; predorsal scales (pockets) 22 ?; snout, $4 \frac{1}{4}$ in head; eye, $3 \frac{7}{8}$; maxillary, $1 \frac{1}{8}$; interorbital, 4 ; head width, $2 \frac{1}{2}$; least depth of caudal peduncle, $2 \frac{7}{8}$.

Body well compressed, moderately long, apparently deepest at dorsal origin, ventral edge rounded convexly and without scutes. Caudal peduncle compressed, its least depth $1 \frac{2}{3}$ its length. Head moderately long, well compressed, little pointed, flattened sides converging below. Snout short, little pointed wide as long, length three-fourths of eye. Eye large, hind edge slightly advanced to center in head length. Mandible forward to nostril, rami low. Maxillary straight, end rather blunt, slightly beyond preopercle ridge and mandibular articulation. Teeth fine, simple, along entire maxillary edge and slightly larger behind. Mandibular teeth equally large. Few small teeth each side of vomer, row on each palatine and broad patch on pterygoids. Nostrils near last third in snout length. Interorbital broadly convex. Cheek nearly an equilateral triangle.

Gill-openings forward about opposite front pupil edge. Gillrakers $20+23$, finely lanceolate, $1 \frac{1}{2}$ in eye. Pseudobranchiae about two-thirds of gill-filaments. Isthmus long narrow ridge, edge not trenchant.

Scales caducous, apparently narrowly imbricated, with about 5 basal striae and 6 incomplete vertical striae above and below marginally. Caudal base evidently scaly.

Dorsal origin about midway between eye center and caudal base, fin base nearly half of head. Anal inserted below last dorsal ray base or a little nearer caudal base than pectoral base. Pectoral (damaged) small, apparently not half way to ventral, which is inserted well before dorsal and depressed fin (damaged) apparently reaching dorsal origin. Vent close in front of anal.

Color in alcohol largely blackish-slate. Sides of head, iris, and broad lateral band on trunk silvery-white, latter about wide as eye. Fins all brownish.

Length, $95 \mathrm{~mm}$. (caudal damaged).

Type-Cat. No. 83165 . U.S.N.M. From Rio Janeiro, Brazil. Wilkes Exploring Expedition.

Only the type known. Comparison with Anchoviella browni (Gmelin) shows it to differ in the more numerous dorsal and anal rays and larger maxillary. A. perfasciata (Poey) has a shorter maxillary. It is deeper bodied than A. eurystole (Swain and Meek), which has a shorter maxillary and broader silvery lateral band. A. fallida Starks ${ }^{1}$ has 40 gill-rakers on the lower limb of the first 
arch, besides more dorsal and anal rays. Engraulis brevirostris Gunther ${ }^{2}$ has: D. 15 ; lateral series of scales, 41 ; depth, $5 \frac{1}{3}$; head, $4 \frac{1}{2}$; eye, $3 \frac{1}{2}$ in head; maxillary dentition exceedingly fine, bone dilated and rounded behind, not extending back to mandibulary joint; dorsal origin midway between snout end and caudal base; lateral silvery band narrower in its anterior third; length, $88 \mathrm{~mm}$.

(Named for San Salvador, an old name of Rio Janeiro.)

\section{Subfamily RASBORINAE.}

\section{RASBORELLA, new genus.}

\section{Type.-Rasborella dubia, new species.}

Body elongate, abdomen rounded. Head moderate. Eyes with free lids. Mouth oblique, moderate, terminal. Premaxillaries protractile. No barbels. Gill-rakers short, lanceolate. Pharyngeal teeth 5-5, edges serrated. Scales moderate and well exposed. Lateral line incomplete. Dorsal fin without osseous ray, inserted between ventral and anal origins. Dorsal and anal about equally large. Caudal forked.

One species.

(Rasbora, the typical Indo-Malayan genus.)

RASBORELLA DUBIA, new species.

Head $3 \frac{3}{4}$; depth $4 \frac{1}{2}$; D. iii, 7,1 ; A. iii, 10, i; P. ii, 14 ; V. i, 7 ; soales 43 in lateral line to caudal base, the first 14 being tubular, and 2 more on caudal base; 12 scales transversely at dorsal and anal origins; 23 predorsal scales; head width 2 in its length; head depth about $1 \frac{2}{5}$; first branched dorsal ray $1 \frac{2}{5}$; first branched anal ray 2 ; least depth of caudal peduncle $2 \frac{7}{8}$; caudal $1 \frac{1}{10}$; pectoral $1 \frac{2}{5}$; ventral $1 \frac{2}{3}$; snout 4 in head from upper jaw tip; eye 3 ; maxillary 3 ; interorbital 3.

Body elongate, well compressed, deepest at ventral origin, body edges all convex. Caudal peduncle well compressed, least depth about $2 \frac{1}{2}$ its length. Head well compressed, lower profile little more inclined than upper and flattened sides but slightly approximated below. Snout convex over surface and in profile, length about fourfifths its width. Eye large, anterior, though hind edge little behind middle in head length. Mouth moderate, well inclined, jaws about even or lower scarcely projects, edges firmly trenchant. Lips thin and developed laterally. Maxillary narrow, largely concealed, nearly extends to eye. Nostrils together, front one simple, near last twofifths in snout and crescentic hind one closely posterior. Interorbital convex. Suborbitals narrow, cover only about one-third of cheek. Opercle and subopercle smooth. Gill-opening forward about last two-fifths in head or not quite to hind eye edge. Gill-rakers $3+12$, 
lanceolate, fine, about two-fifths length of filaments which are $1 \frac{3}{5}$ in eye. Pharyngeal teeth 5-5, hooked and edges strongly serrate.

Scales cycloid, in nearly evenly exposed longitudinal rows, those on middle of sides largest; 2 to 5 basal radiating striae; sometimes several short apical marginal striae; circuli coarse, 17 to 20 ; fins scaleless, except few scales on caudal base; ventral axilla with small scale. Spawning male with 4 pearl organs on lower surface of each mandibular ramus, also cluster of smaller or minute symphyseal ones and several around snout edge; no other tubercles now apparent.

Dorsal origin little nearer caudal base than hind eye edge, first branched ray highest and fin extends nearly half way to caudal base. Anal inserted about last two-fifths of dorsal base, first branched ray highest and reaches base of last. Caudal moderately forked, lobes pointed and rudimentary rays moderate. Pectoral low, reaches slightly over two-thirds to ventral. Latter inserted well before dorsal, reaches about four-fifths to anal, not to vent, which is close before anal.

Color in alcohol: Back warm sepia, fading paler on abdomen, the under surface being glossed with bright silvery white; sides of head especially bright; iris silvery white; sides of body punctuated with minute dark brown dots which extend to anal; fins dull uniform brownish. Length $60 \mathrm{~mm}$.

Type.-Cat. No. 83278, U.S.N.M., no data. Paratypes, two examples, also without data, have the head $3 \frac{4}{5}$ to 4 ; depth $4 \frac{1}{4}$ to $4 \frac{2}{3}$ in standard body length; D. iii, 7, i; A. iii, 10, i; scales 42 or 43 in lateral line to caudal base and 4 more on latter. First 10 to 12 scales of 1.1 distinctly tubular; 10 scales transversely at dorsal and anal origins; 22 to 25 predorsal scales; snout $3 \frac{3}{4}$ to $3 \frac{7}{8}$ in head; eye 3 to $3 \frac{1}{4}$; maxillary 3 to $3 \frac{1}{8}$; interorbital $2 \frac{3}{4}$ to 3 .

Although the locality is given as "Oahu or Fiji?" such is evidently entirely erroneous, and the species may have been procured in the Old World, possibly the Indo-Malayan region?. It cer-. tainly differs from any North American cyprinoid known to us in the remarkable combination of its characters. In a general superficial way it is suggestive of certain species of the American genus Notropis. Its relationship should be sought, however, in the Rasborinae. Among the known forms of this group it would appear unique in its small scales and uniserial pharyngeal teeth. Specifically it bears considerable resemblance to Barilius evezardi Day, but differs in many striking characters, as its incomplete lateral line, larger fins, narrow suborbitals, and pharyngeal teeth. In $B$. evezardi only one row of scales intervenes between the lateral line and ventral origin. In Rasborella dubia at least 2 , or even 3 , would occur: if the lateral line were complete.

(Dubia, doubtful.) 
UROPTERYGIUS FIJIENSIS, new species.

Head $10 \frac{3}{5}$; depth 22 ; snout 7 in head; gape 3 ; interorbital $9 \frac{1}{4}$; mandible $2 \frac{1}{4}$. Body moderately compressed. Tail slightly less than combined head and trunk. Head small, well compressed, width 4 in its length. Snout conic, width $1 \frac{1}{4}$ its length. Eye moderate, closer to lip than interorbital, $1 \frac{3}{4}$ in snout. Gape moderate, hind pupil edge about midway in its length, completely closes. Lower jaw trifle shorter than upper. Lips rather firm, somewhat fleshy. Teeth conic, above biserial and lower biserial behind; upper inner row longer than outer, depressible; about 8 large caninelike depressible teeth in front of upper jaw; row of firm subequal lower teeth and in front inside 5 enlarged depressed teeth; vomer with single row of firm conic teeth. Front nostril short tube each side of snout tip; hind nostril simple pore, well elevated in interorbital over front pupils edge. Interorbital convex. Gill-opening about long as eye. No fins. End of tail compressed to narrow and rather thin edge which extends short space forward above and below.

Color in alcohol: Deep or dark burnt umber, marked everywhere with numerous large blackish blotches, all of which are largely uniform dark. On pharnyx blackish blotches merged more or less to form elongate streaks. Blotches of dark color on head small. Length $582 \mathrm{~mm}$.

Type.-Cat. No. 82774, U.S.N.M., Fiji. Wilkes Exploring Expedition. Only the type known. The species differs from the preceding in the color pattern, different physiognomy of the head, and uniform color of the dark blotches. According to the original color sketch obtained at Lebukea, Fiji, in May, 1840.

(For the Fiji Islands.)

HYPORHAMPHUS SALVATORIS, new species.

Head, $4 \frac{3}{4}$ depth, $7 \frac{3}{4}$; D. ii, 14; A. ii, 14; P. i, 10; V. i, 5; scales 63 in lateral series from shoulder to median caudal base and 6 more on latter; 40 predorsal scales to head; 7 scales above lateral line to dorsal origin, 1 scale below to anal origin; snout $2 \frac{7}{8}$ in head from upper jaw tip ; eye, 4 ; maxillary, $3 \frac{3}{4}$; interorbital, $3 \frac{1}{2}$; combined postocular region and eye, $2 \frac{1}{8}$ in beak. Body well compressed, deepest about midway in predorsal. Caudal peduncle well compressed, about long as deep or least depth $4 \frac{1}{4}$ in head. Head well compressed, flattened sides moderately approximated below, width about 3 in its length. Snout depressed, triangular as seen from above with length four-fifths its width. Eye large, rounded, close to upper profile and hind pupil edge about midway in head length. Maxillary largely concealed, vertical, apparently reaching front nostril. Teeth fine, simple, in narrow bands in jaws, lower much narrower; no vomerine teeth. Tongue depressed, pointed, free. Preorbital nearly 
square, length about three-fifths of eye. Interorbital level. Distinct ridge from behind and above eye to shoulder. Gill-opening extends forward nearly to front eye edge. Gill-rakers $12+28$, lanceolate, about three-fourths of filaments, which are $1 \frac{4}{5}$ in eye. Isthmus narrow frenum. Scales moderately exposed. Small scales on caudal base, and if present? on dorsal and anal, now fallen. Scales with 1 to 5 rather short marginal radii, circuli not complete and moderate. Dorsal inserted much nearer ventral origin than caudal base. Anal similar, opposite. Caudal (damaged) apparently forked? Pectoral small, rather high, about 2 in head. Ventral inserted about midway between gill-opening above and caudal base, fin 3 in head or $2 \frac{1}{3}$ to anal. Vent close before anal.

Color in alcohol: Dark or dusky (evidently discolored). Narrow pale line, likely silvery-white when fresh, from shoulder to caudal base medially and expended about equal to pupil width between dorsal and anal. Fins brown.

Length, $185 \mathrm{~mm}$. (caudal tip damaged).

Type.-Cat. No. 83286, U.S.N.M. Rio Janeiro, Brazil. Wilkes Exploring Expedition.

This species differs from any in the genus we have examined in the increased gill-rakers. H. kronei Ribeiro ${ }^{3}$ has fewer scales (56) and its gill-rakers are not known.

(Named for Rio Janeiro, early known as San Salvador.)

STRONGYLURA TAHITIENSIS, new species.

Head $5 \frac{1}{3}$; depth $1 \frac{1}{3}$ in postocular; D. ii, 14 ; A. ii, 17 ; P. I, 11; V. i, 5 ; scales 315 from shoulder to caudal base medially and 15 more on latter; 206 predorsal scales to head; end of frontal process $3 \frac{2}{5}$ in rest of head posteriorly; snout width $1 \frac{1}{4}$ in frontal process to eye; eye $2 \frac{3}{5}$ in postocular; interorbital $2 \frac{1}{3}$; combined eye and postocular at least 2 in beak (broken). Body partly cylindrical, rather broad above. Caudal peduncle, and body between dorsal and anal, depressed, least depth 3 in its length or $1 \frac{1}{2}$ in eye. Head with flattened sides moderately convergent below, width $1 \frac{2}{3}$ in postocular. Jaws slender, depressed. Eye close to upper profile, ellipsoid. Maxillary nearly reaches pupil, only upper half concealed. Band of outer teeth sharply pointed, small and a series of well spaced larger inner ones. Triangular nasal cavity long as pupil. Interorbital level, with slight though broad shallow median depression and bony surface with many rather deep-set parallel grooves or lines. Gill-opening forward nearly to front pupil edge. Gill-filaments $1 \frac{3}{4}$ in eye. Scales adherent, narrowly imbricated, circuli 38 to 42 , usually incomplete above and below, sometimes only one or a few of central

3 Ann. Mus. Rio Janeiro, vol. 17, 1915, p. 3, Iguape, Brazil. 
united. Cheeks with about 19 scales to opercle ridge. Dorsal with only a very few small scales at basal front edge. Anal with similar patch covering first simple ray and fin base narrowly to base of third branched ray. Caudal base finely scaled. Lateral line extends abruptly up till midway along side of caudal peduncle close after end of dorsal fin, where furnished with very slight keel. Lateral line in front with branch extending entirely to lower pectoral axilla. Dorsal inserted slightly behind last fourth between hind eye edge and caudal base, first branch ray $1 \frac{1}{3}$ in postocular. Anal inserted at last third between pectoral origin and caudal base, similar to dorsal, first branched ray $1 \frac{1}{8}$ in postocular, Caudal (tips damaged) apparently moderately forked, lower lobe longer and at least half an eye-diameter longer than postocular. Pectoral long as postocular. Ventral $1 \frac{3}{5}$ in postocular, and its origin slightly nearer caudal base than preopercle ridge. Vent close before anal.

Color in alcohol: Largely dull brownish, sides and below paler, evidently silvery-white when fresh. Obscure silvery streak, not wider than pupil, from shoulder till below dorsal, where expanded about two-thirds vertical eye-diameter in width, though not distinct beyond fin. Fins all brownish. Length $640 \mathrm{~mm}$. (beak and caudal tips damaged).

Type.-Cat. No. 83424, U.S.N.M., Tahiti. Wilkes Exploring Expedition.

Known from the above example, now in good condition after its long preservation in alcohol. We first thought it identical with $B e$ lone urvillii Valenciennes, unknown since its original description. According to Valenciennes its head is $2 \frac{2}{3}$ times in the entire body, our example showing at least $3 \frac{1}{4}$; suborbital of $B$. urvillii somewhat fastooned, covered like whole surface of jaw and opercle with scales, a character not yet found in other species, our example showing a rather smooth suborbital with traces of but very few scales; long pointed opercle of $B$. urvillii 5 times from opercle border to end of caudal, which is rounded, and in our example emarginate caudal about 9 times to end of caudal; dorsal and anal elevated, height of more elongated rays of last equals length of fin base in B. urvillii, and in our example lobe of anal only slightly over half of anal fin base; $B$. urvill $i^{4}$ apparently green on back and broad silvery longitudinal band, also broad blue-black band along dorsal and anal bases, though no traces of this on our example.

Our species also approaches Belone angusticeps Gunther, ${ }^{5}$ based on an example $275 \mathrm{~mm}$. long, in its fin-rays, though it is said to have the eye 4 in postorbital. 
But few species of Strongylura are known from Polynesia, and in the region where our specimen was obtained only S. gigantae (Schlegel) and S. choram (Forkal) are known.

(For the Island of Tahiti.)

\section{STRONGYLURA AULOCEPS, new species.}

Head about 3 ; depth 12 in postocular region; D. ii, 21 ; A. ii, 20; P. I, 13; V. I, 5; scales about 300 from shoulder to caudal base medially and 15 more on latter; about 218 predorsal scales to head; end of frontal process to eye $3 \frac{1}{3}$ in rest of beak, width equals its length; eye about 3 in postocular; interorbital 17. Body subcylindrical, surface apparently rounded or evenly convex, caudal peduncle compressed, width about half its least depth and latter about $1 \frac{1}{3}$ in eye. Head with flattened sides moderately constricted below, width $1 \frac{3}{5}$ in postocular. Jaws not completely closing for at least basal two-fifths of beak. Eye close to upper profile and combined with postocular $1 \frac{7}{8}$ in beak. Maxillary concealed, extends slightly beyond front eye edge though not quite to pupil. Moderately wide band of outer small sharp-pointed teeth, row of inner larger close-set, though more so toward base of beak. Triangular nasal cavity slightly longer than pupil. Broad interorbital about level. Very shallow wide median depression extends to occiput and with slight median ridge. Distinct depression at postocular each side and another each side of occiput. Squamous area on occiput extending forward barely half way to eyes. Gill-opening extends forward to front nasal cavity edge. Very few slightly rudimentary tubercles substitute for gill-rakers. Gill-filaments about half of eye. Scales very small, crowded, largely adherent and not on dorsal or anal, though cover caudal base completely. Scales with 32 to 44 usually complete circuli. Cheeks with 19 scales to preopercle ridge, beyond which none extend. Slight branch from lateral line extends upward toward pectoral base, but without any keel along side of caudal peduncle. Dorsal origin slightly behind anal origin, at last third between pectoral origin and caudal base, front lobe of fin apparently not much over two-fifths its entire length. Anal similar, though base of last ray distant from caudal base at least for space equal to that between hind eye edge and preopercle ridge. Caudal (damaged) apparently moderately emarginate. Pectoral (damaged) about long as postocular, uppermost ray moderately large. Ventral inserted about midway between hind eye edge and caudal base, fin $1 \frac{1}{6}$ in postocular, though reaches more than halfway to rent, not quite halfway to anal.

Color in alcohol: Faded dull brownish generally. Sides and lower surfaces with traces of silvery. Fins all brownish.

Length, $485 \mathrm{~mm}$. (end of beak and caudal damaged). 
Type-Cat. No. 83422, U.S.N.M., Fiji or Samoa. Wilkes Exploring Expedition.

Though listed from Fiji or Samoa, the original label simply gives Fiji. It approaches S. choram (Forskal) and S. crocodila (Le Sueur) in a general way, but the sculpturing on the head above is more prominent, and in fact more so than in any species of the genus we examined. The entirely naked opercles are also features not noticed in the other species. The origin of the anal appears slightly abortive, possibly damaged at some time, and therefore the species may normally have 1 or 2 more anal rays.

(A $\mathcal{u}$ os, channel; $\kappa \epsilon \varphi a \lambda \dot{\eta}$, head; with reference to the depression on top of the head.)

\section{STRONGYLURA FIJIENSE, new species.}

Head, $3 \frac{1}{4}$; depth, $1 \frac{1}{4}$ in postocular; D. ii, 22 ; A. ii, 16; P. I, 12 ; V. I, 5; scales about 450 from shoulder to caudal base and 12 more on latter; about 325 scales before dorsal to head; preorbital process to eye $5 \frac{1}{4}$ in rest of beak, width about equals its length; eye $2 \frac{1}{3}$ in postocular; interorbital $1 \frac{3}{4}$. Body compressed moderately, though sides slightly cylindrical. Caudal peduncle compressed, width threefourths its least depth, which is $1 \frac{3}{5}$ in eye. Head with flattened sides moderately constricted below, width $1 \frac{2}{3}$ in postocular. Jaws not completely closing for at least basal fourth of beak. Eye close to upper profile and combined with postocular $2 \frac{2}{5}$ in beak. Maxillary concealed, narrow, extends slightly beyond eye front, though not quite to pupil. Outer band of fine teeth of moderate width, minute, close set, sharp pointed. Inner row of well-spaced larger teeth become much smaller toward end of jaws. Triangular nasal cavity $1 \frac{1}{4}$ in pupil. Moderately broad interorbital level, with narrow median shallow depression, broadening and deeper behind eye to occiput, though no lateral postocular depression. Gill opening extends forward opposite hind nasal cavity edge. Few slight rudimentary tubercles substitute for gill-rakers. Gill filaments $1 \frac{4}{5}$ in eye. Scales extremely small, crowded closely, adherent, not extending on dorsal and anal, though caudal base scaly. Scales with 17 to 28 basal and 30 to 52 apical circuli, usually vertical, parallel and unconnected. Cheeks with 24 scales to preopercle ridge, beyond which 6 more, though none on opercle. Slight branch from lateral line extends upward toward pectoral base, and moderate keel alongside of caudal peduncle and caudal base. Dorsal origin a little behind anal origin or about last third between pectoral origin and caudal base, front lobe of fin about $3 \frac{1}{2}$ ? in its length (last ray damaged). Anal similar, though base of last ray distant from caudal base for space slightly greater than postocular. Caudal (damaged) apparently emarginate. Pectoral (damaged) slightly longer than post- 
ocular. Ventral inserted slightly nearer caudal base than hind eye edge, fin little less than postocular, reaches $2 \frac{1}{4}$ to vent or $2 \frac{4}{5}$ to anal.

Color in alcohol: Faded dull brownish generally. Sides and lower surface paler, evidently silvery white. Fins all brownish. Length. $738 \mathrm{~mm}$. (caudal tips damaged).

Type-Cat. No. 83421, U.S.N.M., Fiji or Samoa in list, though original label gives Fiji. Wilkes Exploring Expedition.

This species is unique among all members of the genus in the greatly increased number of scales.

(Named for the Fiji Islands.)

LEPTHAEMULON, new subgenus.

Type.-Orthopristis rhabdotus, new species.

This section of Orthopristis is distinguished by the increased gillrakers and slender body, in the latter character approaching. Evapristis Jordan and Evermann. Besides the weakly armed preopercle, the fins are scaleless.

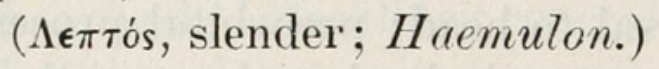

\section{ORTHOPRISTIS RHABDOTUS, new species.}

Head $3 \frac{1}{8}$; depth $3 \frac{3}{5}$; D. XIII, 14 , i A. III, 12 , i P. ii, 16 ; V. I, 5 ; scales in 64 rows close along and above lateral line to caudal base; tubes 50 in lateral line to caudal base and 10 more in latter; 9 scales above lateral line to spinous dorsal origin, 10 above to soft dorsal origin, and 14 below to spinous anal origin; 50 predorsal scales: head width $2 \frac{1}{10}$ in its length; head depth at hind preopercle edge $1 \frac{1}{3}$; fourth dorsal spine (tip damaged) about $2 \frac{1}{4}$; first dorsal ray 3 ; third anal spine $5 \frac{4}{5}$; first anal ray $3 \frac{1}{3}$; lower caudal lobe $1 \frac{2}{5}$; pectoral $1 \frac{1}{8}$; ventral 2 ; snout $3 \frac{1}{2}$ in head from upper jaw tip; eye 4 ; maxillary $3 \frac{1}{2}$; interorbital $3 \frac{1}{3}$.

Body elongately fusiform, well compressed, deepest slightly forward and predorsal with slight keel, edges otherwise convex. Caudal peduncle well compressed, least depth $1 \frac{1}{2}$ its length or $4 \frac{1}{6}$ in total head length.

Head compressed, flattened sides slightly approximate below. Snout conic, long as wide. Eye round, little elevated, and hind edge very slightly before center in head length. Mouth small, closed lower jaw slightly protrudes. Maxillary with upper edge completely ensheathed by preorbital, extends beyond hind nostril though not quite to eye; expansion about half of eye. Teeth, small, simple, conic, in bands in jaws and outer row slightly enlarged. No teeth on mouth roof. Nostrils close together, similar vertical slits; front one about last third in snout; hind one slightly elevated. Interorbital convexly elevated. Preopercle armed with short weak denticles. Suprascapula entire. 
Gill-opening forward opposite hind nostril. Gill-rakers $15 \div 20$, slender, lanceolate, $1 \frac{3}{5}$ in filaments, which are long as eye. Pseudobranchiae half of gill-filaments.

Scales in oblique rows above lateral lines, becoming horizontal behind, and rows below all horizontal. Scales become smaller along body edges, head above and below, and on breast. Caudal base scaly, fin covered with fine scales. Soft dorsal and anal, each with narrow basal strip of fine scales. Cheek with 16 rows of scales. Snout, preorbital, maxillary, and lips naked. Scales with 11 basal radiating striae, apical denticles 39 to 46 and circuli moderately fine. Lateral line largely concurrent with dorsal profile, inclined little at first along caudal peduncle side until midway at caudal base; tubes small, simple.

Spinous dorsal inserted close behind pectoral base; fourth spine longest and last spine twice first; fin edge entire. Soft dorsal origin slightly nearer that of spinous dorsal than caudal base; front rays elevated, but without distinct lobe. Spinous anal inserted nearly midway between fifth dorsal spine base and caudal base; spines graduated to last, though second but very slightly less than third. Soft anal like soft dorsal, only much shorter. Caudal emarginate, pointed lobes about equal. Pectoral falcate, reaches two-thirds to anal. Ventral inserted close behind pectoral base, halfway to vent.

Color in alcohol dull olive-brown, sides and below paler. Following courses of scales above lateral line a dark median line on each row, at least wide as pale interspaces; these lines oblique on anterior half of back, more or less horizontal on posterior portion. Below horizontal dark lines, equally wide, though fewer; some cross lateral line posteriorly and more or less traverse junctures of scales. Fins all deep brownish. Pectoral axil slaty. Iris brown.

\section{Length $250 \mathrm{~mm}$.}

Type.-Cat. No. 83484, U.S.N.M., Peru? Wilkes Exploring Expedition.

Only the type known. It differs from the known species of the genus in the increased gill-rakers.

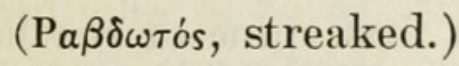

Ctenosciaena, new subgenus.

Type.-Sciaena dubia, new species.

Differs from the subgenus Sciaena in the slender, elongate, lanceolate gill-rakers, which are at least as long as longest filaments. Other characters in combination, are the apparently ctenoid scales (of which but few remain); minute teeth, in narrow bands; long maxillary, reaching nearly to hind eye edge; presence of a well-developed single barbel at chin; reduced soft dorsal rays; presence of 2 anal spines, 
with second enlarged and apparently nearly as long as soft anal fin; cavernous snout or muzzle and suborbital region; presence of large pseudo-branchiae; soft dorsal and anal largely scaly from bases.

(K $\tau \dot{\epsilon} \iota s$, comb or gill-raker; Sciaena.)

\section{SCIAENA DUBIA, new species.}

Head, $3 \frac{1}{4}$; depth, $3 \frac{1}{4}$; D. X, I, 23; A. II, 8, i; P. ii, 18; V. I, 5; tubular scales (fallen) according to estimated pockets about 42 ? from shoulder to caudal base; head width, $2 \frac{1}{10}$ in its length; snout 4 ; eye, $3 \frac{1}{4}$; maxillary, $2 \frac{2}{5}$; interorbital, 4 ; fourth dorsal spine, $2 \frac{1}{6}$; second anal spine, $2 \frac{1}{10}$; pectoral, $1 \frac{2}{5}$; ventral, $1 \frac{4}{5}$.

Body elongate, compressed, rather fusiform. Caudal peduncle well compressed, least depth about $1 \frac{1}{4}$ in its length or about 3 in head.

Head compressed. Snout convex, length three-fourths its width. Eye elevated, hind edge about midway in head length, its diameter greater than snout. Mouth rather large, and lower jaw included. Maxillary reaches first three-fifths in eye, its upper edge entirely ensheathed by preorbital; expansion 3 in eye. Chin with 4 pores short median barbel. Teeth fine, minute, in narrow band in each jaw; no others. Hind nostril vertical slit, much longer than front one, which simple round pore midway in snout. Hind preopercle and suprascapula edges entire.

Gill-opening forward about to eye center. Gill-rakers $8+14$, equal filament's or about $2 \frac{1}{2}$ in eye.

Scales mostly all fallen, few remaining ctenoid, in rows (according to pockets) apparently more or less parallel with lateral line above and horizontal below. Small scales on dorsal and caudal basally, and largest and narrowly imbricated along sides medially. Scales show about 6 basal radiating striae and about 30 short apical denticles, and circuli very fine. Lateral line apparently mostly concurrent with dorsal profile, little high along caudal peduncle side and tubes trifid.

Spinous dorsal inserted over pectoral origin, fourth spine apparently longest and first shortest. Soft dorsal inserted nearly midway between front pupil edge and caudal base, front rays slightly longer. Anal inserted nearer to caudal base than to pectoral, and second spine enlarged, greatly longer than very short first spine or reaches halfway to caudal base. Pectoral reaches at least three-fifths to anal.

Color in alcohol: Back dull slaty brown, belly and lower surface pale with silvery-white sheen. Fins and iris all dull brown.

Length, $124 \mathrm{~mm}$.

Type-Cat. No. 83309, U.S.N.M. No locality. Wilkes Exploring Expedition.

Only the above example known, and as it appears more closely allied with the Indian species it may likely have been obtained in the Philippines? It is also, unfortunately, in very poor condition. Re- 
markable for the combination of characters it exhibits, in many ways it resembles Sciaena russeli (Cuvier), but differs at once in the long gill-rakers. S. russeli, like $S$. dussumieri (Valenciennes), is evidently quite variable. It apparently has a much longer mental barbel, lower spinous dorsal, and usually longer maxillary. In the last character we find an example in the academy from the Philippines showing it only reaching opposite to the eye center, whereas in smaller examples, which Fowler lists as $S$. dussumieri, ${ }^{6}$ it reaches the hind eye edge. These examples, all in the Academy of Natural Sciences, show: Head 3 to $3 \frac{1}{3}$, or $2 \frac{2}{3}$ in young; depth 3 to $3 \frac{1}{8}$, or $3 \frac{1}{4}$ in young; D. X, I, 25 to 27 , i; A. II, 7 , i; scales close above and along lateral line 50 to 56 to caudal base; tubes about 48 in lateral line to caudal base; 7 scales above lateral line to spinous dorsal origin; 39 or 40 predorsal scales; snout $3 \frac{1}{5}$ to $3 \frac{7}{8}$ in head, 4 in young; eye $4 \frac{1}{3}$ to 5,3 in young; maxillary $2 \frac{1}{3}$ to $2 \frac{7}{8}, 2 \frac{1}{8}$ in young; interoribital $3 \frac{3}{4}$ to 4 . Contour elongately ovoid, back but slightly elevated; length of caudal peduncle four-fifths its least depth, which 3 to $3 \frac{1}{10}$ in head, $3 \frac{2}{5}$ in young. Head width 2 to $2 \frac{3}{4}$ in its length. Snout convex, length $\frac{4}{5}$ to $\frac{7}{8}$ its width. Eye little elevated, 1 to $1 \frac{1}{2}$ in snout; snout length three-fourths of eye in young; hind eye edge about midway in head length, little advanced in half grown and little backward in young. Maxillary reaches eye center, but little short of hind edge in half-grown and young; expansion $1 \frac{3}{4}$ to $1 \frac{7}{8}$ in eye. Teeth fine, in bands in jaws, outer upper little enlarged; lower fine, small. Snout end with 6 porelike slits, of 3 uppermost median highest, alike; each lower lateral cleft to upper lip; chin with 4 pores, small one on front of barbel at base; barbel $1 \frac{2}{5}$ to $1 \frac{1}{2}$ in eye. Front nostril at least two-fifths in snout; hind one three times as large, slightly inclined slit midway between front one and snout. Interorbital convex. Hind preopercle edge rather weakly denticulated, little larger denticles in young. Gill rakers i, $5+8$, ii, short points, barely one-fourth of filaments, which are $1 \frac{3}{4}$ in eye; pseudobranchiae large. Scales ctenoid, in oblique rows crossing lateral line; smaller on predorsal, along soft dorsal base and out in caudal; both latter fins largely, also soft anal, with small scales; basal radiating striae 10 to 16 ; apical denticles 31 to 54 ; circuli fine; 10 rows of cheek scales; lateral line largely concurrent with dorsal profile at first, falls until horizontal close behind anal; tubes trifid or bifid. Third dorsal spine $1 \frac{7}{8}$ to 2 in head; first anal ray $2 \frac{2}{3}$ to $3 \frac{2}{3}$; second anal spine $2 \frac{1}{2}$ to $2 \frac{4}{5}$; second anal ray 2 to $2 \frac{1}{8}$; caudal with median rays forming obtuse point behind, $1 \frac{1}{4}$ to $1 \frac{1}{2}$; pectoral $1 \frac{1}{4}$ to $1 \frac{2}{5}$; ventral $1 \frac{1}{2}$ to $1 \frac{3}{5}$. In alcohol dull brown, paler below. Spinous dorsal dusted with dusky, paler dots on soft dorsal. Iris slaty. Length 63 to $173 \mathrm{~mm}$.

${ }^{6}$ Copeia, No. 58, June 18, 1918, D. 64.

5596-24-Proc.N.M.vol.63 35 
We have also examined S. macroptera (Bleeker) from Sumatra, material in the academy, and it differs not only in the short gillrakers, but also more numerous dorsal rays. $S$. dussumieri we have not seen, and it is said to have cycloid scales. Umbrina broussonetii Cuvier is described from "mer du Sud et de la Jamaica," 7 though no member of the family is known from Polynesia. The Jamaican fish has 25 soft dorsal and 6 soft anal rays.

\section{PARALARIMUS, new genus.}

\section{Type.-Paralarimus patagonicus, new species.}

Caudal peduncle slender, rather short. Mouth inclined moderately, cleft not vertical. Lower jaw protrudes. No mental barbels. Teeth permanent in both jaws, sharp, conic, outer enlarged and few upper as canines. Interorbital moderate. Preorbital rather narrow, flat. Preopercle edge membraneous, weakly fringed. Scales of lateral line not noticeably larger than those adjacent or concealed by smaller ones. Caudal moderately scaled basally, naked terminally. Pores at snout tip and mandible tip obsolete. Gill-rakers in moderate number, elongate. Pseudobranchiae well developed. Skull firm. Anal inserted posteriorly, small, first spine nearer caudal base than ventral origin.

This genus falls in the Sciaeninae. It is allied with Larimus in its moderately firm and not excessively cavernous skull, moderate interorbital width, oblique mouth with projecting mandible, maxillary slipping below preorbital nearly its whole length, and general physiognomy. It differs in the more or less larger unequal biserial upper teeth. It likewise differs from Odontoscion, which also has fewer dorsal and anal rays. From Corvula it differs in the absence of canines, and from the fluviatile tropical American Plagioscion, in the scales of the lateral line not larger than those adjacent.

\section{(Пиюа, near; Larimus.)}

\section{PARALARIMUS PATAgONICUS, new species.}

Head $2 \frac{7}{8}$; depth $3 \frac{1}{3}$; D. X, I, 22 ; A. II, 7, i; P. ii, 13 ; V. I, 5 ; scales abount 60 , counted close above lateral line to caudal base; tubes 49 in lateral line to caudal base; 10 scales (damaged) above lateral line to spinous dorsal origin, 9 above to soft dorsal origin, 9 below to spinous anal origin; predorsal scales about 36 ; head width $2 \frac{1}{6}$ its length; head depth at occiput $1 \frac{2}{7}$; least depth of caudal peduncle $3 \frac{7}{8}$; third dorsal spine 2 ; second anal spine $4 \frac{1}{4}$; second anal ray $2 \frac{1}{2}$; caudal to median ray tip (damaged) $1 \frac{3}{4}$; pectoral $1 \frac{7}{8}$ (tip damaged) ; ventral 2 ; snout $3 \frac{3}{4}$ in head from upper jaw tip; eye $4 \frac{3}{5}$; maxillary 2 ; interorbital $3 \frac{2}{5}$.

7 Hist. Nat. Poiss., vol. 5, 1830, p. 139. 
Body elongately ovoid, deepest at spinous dorsal origin, well compressed. Caudal peduncle well compressed, least depth about $1 \frac{1}{6}$ its length.

Head large, well compressed flattened sides very slightly constricted below. Snout convex in profile and over surface, length four-fifths its width. Eye slightly elevated, rounded, hind edge midway in head length. Mouth large, moderately inclined. Lower jaw protrudes, rather shallow. Maxillary reaches opposite hind pupil edge; expansion $1 \frac{2}{3}$ in eye. Lips rather thin, narrow. Teeth conic, simple, upper form outer row of moderately large well spaced and somewhat caninelike teeth, especially anteriorly, where several perfected canines; inner upper teeth very small close-set continuous row, close inside outer row; lower teeth imiserial, anteriorly small and close-set, laterally larger and wide-set, like upper outer teeth; no others. Tongue depressed, free, rounded in front. Inner buccal membranes moderately broad. Nostrils small, front one about last fourth in snout; hind one nearly twice as large and midway between front one and eye. Interorbital broadly convex, with slight bony superciliary ridge each side. Preorbital width about half of eye. Preorpercle edge membraneous, very slightly fringed. Opercle ends in 2 broad spines, lower slightly more posterior.

Gill-opening forward about opposite front nostril. Gill-rakers $5+11$, lanceolate, slender, long as filaments, which $1 \frac{4}{5}$ in eye. Pseudobranchiae well developed, but little shorter than gill-filaments.

Scales rather loose or caducous, in slightly oblique longitudinal rows before anal, or inclination forward; very weakly ctenoid to cycloid; basal radiating striae 11 to 15 ; apical denticles 10 to 13 ; circuli very fine; scales mostly smaller along body edges, along dorsal bases and in caudal, dorsal and anal basally; 4 or 5 scales in cheek to preopercle ridge. Lateral line slopes from shoulder till horizontal over front of anal and then on over caudal to its tip; tubes rather large, many closely trifid. Suprascapula scaled, with rather long fringe behind.

Spinous dorsal inserted midway between snout tip and fifth dorsal ray base, third spine longest and first much shortest, others graduated down. Soft dorsal inserted about midway between front eye edge and caudal base, front rays (damaged) longest, fin graduated down evidently from first rays. Spinous anal inserted at last third in space between hind eye edge and caudal base, first spine $\frac{1}{5}$ of second, and rays graduated down from first and second which are longest. Caudal elongate (damaged), median rays evidently longest and forming most of the posterior part of fin. Pectoral small, pointed, reaches (damaged) scarcely halfway to anal. Ventral inserted opposite pectoral origin, apparently halfway to anal. Vent half an eye-diameter before anal. 
Color in alcohol gray-brown on back and upper surface of head. Former with a number of narrow pale brown lines, especially distinct below spinous dorsal, and greatly inclined back, all along above lateral line. Sides and lower surface of body pale, with bright silvery-whitish sheen. Fins dull brown. Pectoral ventral and anal paler brown.

Length $162 \mathrm{~mm}$.

Type.-Cat. No. 83222, U.S.N.M., northern Patagonia. Wilkes Exploring Expedition.

Only the type known.

(Named for Patagonia.)

LEPIDAPLOIS TROTTERI, new species.

Head $2 \frac{1}{4}$; depth $2 \frac{1}{4}$; D. XII, 10 ; A. III, 12; P. ii, 15; V. I, 5; scales 32 in lateral line to caudal base and 3 more on latter; 6 scales above lateral line to spinous dorsal origin, 5 above to soft dorsal origin, and 11 below to spinous anal origin; 16 scales in predorsal to occiput medianly; head width $2 \frac{1}{6}$ its length; snout 3 ; eye $5 \frac{7}{8}$; maxillary $2 \frac{3}{4}$; interorbital $3 \frac{2}{3}$; last dorsal spine $4 \frac{1}{2}$; eighth dorsal ray $2 \frac{2}{5}$; third anal spine 4 ; eleventh anal ray $2 \frac{4}{5}$; upper caudal lobe $1 \frac{1}{3}$; least depth of caudal peduncle $2 \frac{1}{4}$; pectoral $1 \frac{2}{3}$; ventral $1 \frac{1}{2}$.

Body ovoid, rather deep, edges convex, compressed. Caudal peduncle strongly compressed, length three-fourth its least depth.

Head conic, compressed, flattened sides about evenly approximate above and below. Snout conic, width $1 \frac{1}{8}$ its length. Eye small, elevated, hind edge about midway in head length. Mouth moderate, jaws even. Maxillary when closed reaches eye, as seen under preorbital groove reaches eye center. Four large canines in front of each jaw, median upper pair and outermost of each below, largest; inner band of low convex teeth in each jaw, narrowing behind. Lower lateral lip wide, thin, $1 \frac{4}{5}$ in eye. Nostrils separate, front one at least fourth in snout; hind one smaller, little higher, and little nearer front one than eye. Interorbital convex. Preopercle entire, sharp behind.

Gill-rakers $7+11$, small, robust, lanceolate, $1 \frac{4}{5}$ in filaments, which are $1 \frac{3}{4}$ in eye. Pseudobranchiae long as gill-filaments.

Scales variable, with 13 to 32 basal radiating striae, few or none extending apically and circuli very fine; head largely covered with small scales; muzzle, most all of mandible, except near articulation, and interorbital, naked; 9 rows of scales on cheek to preopercle ridge; predorsal, back and breast scales little smaller than elsewhere in trunk; smaller scales than on body extend on bases of dorsals and anals, well over each basal half of fin; caudal with basal third covered with large scales; lateral line complete, largely concurrent 
with dorsal profile, falls midway on caudal peduncle behind; tubes small, slightly arborescent, entire on caudal.

First dorsal spine little shorter than eye, and others graduated to last, which is longest, membranes all deeply notched marginally. Soft dorsal much shorter than spinous, though higher, last ray extending back little beyond caudal base. Anal spines graduated from first to third, which is longest, and soft anal like soft dorsal. Caudal emarginate, pointed above and below. Pectoral not reaching anal. Ventral inserted before pectoral base, extends at least as far posteriorly as pectoral tips, and spine slightly less than half length of fin.

Color in alcohol dull brown generally, each scale on trunk with bluish-gray spot, largest size of pupil, which on head form horizontal lines continuous and slightly converging to muzzle. On trunk between longitudinal rows of pale spots equally broad umber-olive lines, darker than general body-color. Bluish spots also extend in scales on bases of dorsals and anals. Blackish blotch on membranes of first to fourth dorsal spines. Below soft dorsal, and including basal two-fifths of fin, deep chocolate-brown or dusky blotch with white saddle on caudal peduncle behind, 3 or 4 scales in width, though dark area slopes attenuated down to origin of lower caudal lube. Pectoral and caudal brown. Ventral and lower broad margin of anals deep brownish-black to blackish. Iris brown. Teeth white.

Length, $290 \mathrm{~mm}$.

Type.-Cat. No. 82970, U.S.N.M., Pomotou Islands. Wilkes Exploring Expedition.

According to the original painting this specimen was captured at Sertes Island, August, 1839. It is shown as morocco-red in back and upper surface of head. Side of trunk peach-red. Side and lower surface of head, and undersurface of trunk lemon-chrome. Lips like side of head. Iris nopal red. At junctures of scales dark longitudinal streaks on back, more reddish and lilac on head and chest. Each scale on trunk with pale or whitish median spot. White blotch before and behind black dorsal blotch, very distinct, and lower also extending well down along lower caudal edge. Other black markings as described from alcoholic specimen, except bloth on dorsal spine not basal, but embraces median region of front of fin. Spinous dorsal yellow, with small, irregular, pale orange blotches. Soft dorsal more reddish and more mottled with dull red. Anal similar. Caudal greenish-yellow terminally, with more reddish tints on rays basally and about upper margin. Pectoral pale or orange.

This species is first noticed by Gunther under the mistaken identity with Labrus macrurus Lacépède. He had a single young example from Vavau, which he calls Cossyphus macrumus. ${ }^{8}$ The other syno-

8 Journ. Mus. Godeffroy, vol. 15, 1881, p. 240, pl. 129, Fig. A. 
nyms he includes are Crenilabrus chabrolii Lesson and Cossyphus maldat Valenciennes, both of which belong with his $C$. bilunulatus, as we have already noticed. Gunther's figure certainly represents L. trotteri, only differing in the minor point of a small blackish blotch at the front of the spinous dorsal. His specimen was 255 $\mathrm{mm}$. long and appears to have been the only one ever obtained. Jordan and Seale credit Gunther's record as $L$. hirsutus, ${ }^{9}$ still perpetuating Gunther's error.

(For Dr. Spencer Trotter, of the chair in biology, in Swarthmore College.)

CHROMIS CUPREUS, new species.

Head, 3 ; depth, 2 ; D. XIII, 12 ; A. II, 12 ; P. ii, 18; V. I, 5 ; scales 21 in upper arch of lateral line, and 12 pores in horizontal section; 4 scales above lateral line to spinous dorsal origin, 3 above to soft dorsal origin, and 13 below to spinous anal origin; 36 predorsal scales; head width, $1 \frac{4}{5}$ its length; fourth dorsal spine, $1 \frac{4}{5}$; fifth dorsal ray, $1 \frac{2}{3}$; second anal spine, 2 ; first anal ray, $1 \frac{7}{8}$; lower caudal lobe (damaged), 1?; least depth of caudal peduncle, $2 \frac{1}{3}$; pectoral, 1 ; ventral, $1 \frac{1}{3}$; snout, $4 \frac{1}{10}$ in head from upper jaw tip; eye, $3 \frac{4}{5}$; maxillary, $2 \frac{4}{5}$; interorbital, 3.

Body deeply ovoid, compressed, predorsal slightly trenchant, profiles alike and deepest about middle of pectoral. Caudal peduncle well compressed, length four-fifths its least depth.

Head deep, compressed, flattened sides slightly approximate below. Snout short, declivous, convex, length three-fifths its width. Eye scarcely elevated, center about first third in head. Mouth small, gape short, and lower jaw very slightly projecting. Maxillary free, reaches eye; expansion $2 \frac{1}{3}$ in eye. Lips free, moderate. Teeth conic, simple, as outer row of larger more robust ones and inner narrow band of smaller ones. Nostril about last third in snout. Interorbital convex. Preopercle and preorbital edges entire. Single short strong opercular spine.

Gill-opening forward opposite nostril. Gill-rakers 9+24, lanceolate, $1 \frac{2}{5}$ in gill-filaments, which $1 \frac{1}{10}$ in eye. Pseudobranchiae large, three-fifths of gill-filaments.

Scales in rows parallel with lateral line, rows converging posteriorly. Smaller scales all along body edges. Small scales over all fins basally, becoming minute and more numerous over rayed fins. Muzzle, except lips, covered densely with small scales, also small scales crowded on top of head and suborbital. Cheek with 8 rows of scales, median row enlarged. Scales with 6 basal radiating striae; apical denticles 90 ; circuli very fine. Tubes in lateral line large,

${ }^{9}$ Bull. Bur. Fish., vol. 25, 1905 (1906), p. 293. 
with 2 or 3 short branches above and same below, and last tube 2 scales from caudal peduncle.

Spinous dorsal inserted little behind pectoral origin, third to fifth spines longest, second spine long as last and first much shortest; fin edge notched. Soft dorsal inserted at last third between spinous dorsal origin and caudal base, depressed fin extending back little farther than latter. First anal spine not quite one-third of second, inserted slightly nearer pectoral origin than caudal base, rayed fin reaching latter as depressed backward. Caudal emarginate, lobes well pointed. Pectoral reaches opposite anal origin. Ventral inserted behind pectoral base, reaching vent, which is close to anal; spine three-fourths of fin.

Color in alcohol dark vandyke brown generally. Sides and below rich dark coppery, a pale coppery area medianly on each scale. Fins all deep brownish, except paler pectoral and front or inner edges of ventral rays, each of which are narrowly quite pale or milky. Iris brown. Axil of pectoral brown, without dark blotch.

Length $157 \mathrm{~mm}$.

Type.-Cat. 83108, U.S.N.M., "Singapore, Maui, Fiji, or Samoa," though most likely from either of the two last named. Wilkes Exploring Expedition.

Only the type known, chiefly to be distinguished by its color.

(Cupreus; copper.)

\section{Family DACTYLOSCOPIDAE.}

GILlellus AUSTRALIS, new species.

Head $4 \frac{1}{4}$; depth 7 ; D. VI-XX, 21 ; A. II, 38 ; P. 15 ; V. 3 ; scales $29+7+32$ in lateral line to caudal base and 2 or 3 more on latter; 3 scales above lateral line at nearest approach to spinous dorsal; 6 scales above lateral line to soft dorsal, 6 below to anal; head width $2 \frac{1}{3}$ in its length; first dorsal spine $8 \frac{1}{4}$; tenth and ray $2 \frac{1}{4}$; least depth of caudal peduncle $4 \frac{4}{5}$; caudal $1 \frac{4}{5}$; pectoral 1 ; ventral $2 \frac{2}{5}$; snout 7 in head from upper jaw tip; eye $6 \frac{1}{3}$; maxillary 4 ; interorbital 2 in eye.

Body elongate, slender, deepest about end of pectoral, strongly compressed. Caudal peduncle strongly compressed, free.

Head conic, wide as deep. Snout convex over surface, length threefifths its width. Eye superior, center at first fourth in head, long as snout. Mouth small, oblique, lower jaw well protruded. Maxillary oblique, to eye center, expansion $1 \frac{1}{2}$ in eye. Teeth in narrow bands in jaws, fine, conic, simple. No teeth on mouth roof. Lips moderate, entire. Nostrils small, superior. Interorbital level. Preopercle entire. Opercle smooth, superior hand flap with fringe of 6 short points, longest about 3 in eye. 
Gill-opening forward opposite hind eye edge. No gill-rakers. Pseudobranchiae about three-fifths of gill filaments, which are $1 \frac{1}{8}$ in eye.

Scales mostly fallen, in even longitudinal rows. Caudal scaly basally, other fins naked. Head naked. Scales with 19 to 25 basal marginal striae, of which 2 to 6 are incomplete. Lateral line complete, slopes down behind depressed pectoral midway along side, $\operatorname{arch} 2 \frac{3}{4}$ in horizontal section. Tubes in lateral line simple, rather large, each well exposed.

Dorsal spines all flexible. First dorsal spine inserted over middle of opercle and with succeeding 5 all separated, without membranes, and of uniform height; other dorsal spines uniform and scarcely distinguished from dorsal rays of soft fin. Anal begins little before origin of second spinous dorsal or one connected by membranes, fin edge little more notched. Caudal elongate, median rays longest and forming point behind. Pectoral large, pointed. Ventral inserted before first spinous dorsal, reaches anal.

Color in alcohol pale brownish, evidently little paler below. Back and upper surface of head finely specked with obscure brown dots or small blotches, these also on dorsals and caudal. Along back traces of about 12 small dark-edged saddles. Two pale lines extend from eye, one backward and other more inclined in same direction.

Length $87 \mathrm{~mm}$.

Type-Cat. No. 83315, U.S.N.M., Valparaiso, Chile. Wilkes Exploring Expedition.

Also Cat. No. 83099, U.S.N.M., paratype, same data. It shows: Head $4 \frac{1}{4}$; depth 7 ; D. VI-XX, 22 ; A. II, 39 ; scales $33+6+31$ in lateral line to caudal base and 2 more in latter; snout $7 \frac{1}{5}$ in head from upper jaw tip; eye $6 \frac{1}{4}$; maxillary $3 \frac{2}{3}$; head width $2 \frac{3}{4}$; length $68 \mathrm{~mm}$.

This species is related to G. semicinctus Gilbert, from the Gulf of California and Florida, but differs in its more slender body and increased scales and fin rays. Probably Dactyloscopus zelotes Jordan and Evermann is also a Gillellus, as it is described with "dorsal beginning in the nape, its distance from snout about equaling depth of body, the first 6 rays shorter than those following and not connected by membrane; as no traces of articulation can be found, they are probably flexible spines, but are not clearly differentiated from those immediately following." As D. zelotes has been set aside as the type for the nominal subgenus Esloscopus Jordan and Evermann, probably the latter had best be merged with Gillellus rather than with Dactyloscopus.

(Australis, southern.) 
SALARIAS McCULLOCHI, new species.

Head $4 \frac{2}{5}$; depth $4 \frac{2}{5}$; D. XIII, 23 ; A. 23 ; P. 14 ; V. 2 ; snout $3 \frac{1}{3}$ in head; eye $4 \frac{1}{3}$; maxillary $2 \frac{1}{2}$; interorbital $5 \frac{1}{5}$; first dorsal spine $1 \frac{2}{3}$; fifth dorsal ray $1 \frac{1}{2}$; fourth anal ray $2 \frac{1}{6}$; least depth of caudal peduncle $2 \frac{1}{2}$; caudal $1 \frac{1}{10}$; pectoral 1 ; ventral $1 \frac{4}{5}$; head with $1 \frac{1}{2}$.

Body slender, elongate, strongly compressed, deepest at middle of depressed pectoral. Caudal peduncle strongly compressed, not free above.

Head small, sides and cheeks little swollen and lateral surfaces more convergent above. Snout very obtuse, front profile nearly vertical, surface broadly convex, length two-thirds its width opposite front of eyes. Eyes moderate, well elevated anteriorly, center near first fourth in head. Mouth broad, gape short, moderately inferior or front of lower jaw at least slightly before eye. Maxillary extends back far as hind eye edge. Upper lip crenulate and lower entire. Teeth fine, movable in lips, even, close set, incisor like. No lower canines. Nostril with small flap, about one-fourth of eye, situated slightly above lower eye edge.

Gill-opening with broad free fold across isthmus. Gill-rakers $3+10$ ? short weak points barely one-fifth of filaments, which equal eye. Pseudobranchiae about two-thirds of gill-filaments.

Skin smooth. No crest or nuchal filaments. Palmate supraorbital tentacle half diameter of eye in length. Row of pores over suborbital and close behind eye, and another down along preopercle. Lateral line declivous over end of depressed pectoral, then obsolete.

Spinous dorsal origin slightly before hind edge of gill-opening, spines uniformly high forward, few of last ones graduated down. Soft dorsal origin little nearer caudal base than snout tip; fin uniformly high and last ray joined with caudal by low membrane.

Color in alcohol dull brownish generally, under surfaces greatly paler or with tints of dull water green. Dull buff band from front surface of snout across preorbital, lower side of head, including upper front pectoral base, then midway along side to caudal base medially. Obscure narrow buff-brown line parallel along and including lateral line. Fins all dull brown.

Length $90 \mathrm{~mm}$.

Type.-Cat. No. 83293, U.S.N.M., Billinghausen Island. Wilkes Exploring Expedition.

Only the above specimen known. It differs strikingly from the other Polynesian species in its coloration, the median lateral yellowish longitudinal band appearing very pronounced.

(Dedicated to Dr. Allan R. McCulloch the accomplished zoologist of the Australian Museum.) 
Head $3 \frac{2}{5}$; depth, $2 \frac{1}{3}$; D. 77 ; A. 57 ; P. i, $9 ;$ V. i, 5 ; about 92 tubes in lateral line to caudal base; scales 103 in lateral line to caudal base; 36 scales above lateral line, 40 below; longest dorsal ray $2 \frac{1}{8}$ in head; longest anal ray $2 \frac{1}{3}$; least depth of caudal peduncle $2 \frac{2}{5}$; right pectoral 3 ; left pectoral $2 \frac{1}{5}$; caudal $1 \frac{1}{5}$; head width $4 \frac{2}{3}$; snout $4 \frac{1}{5}$ in head, from upper jaw tip to upper eye; upper eye $6 \frac{1}{4}$; maxillary $2 \frac{1}{10}$.

Body strongly compressed, contour ellipsoid or greatest depth median in its length. Caudal peduncle strongly compressed, length about two-fifths its least depth.

Head greatly compressed, upper profile slightly concave above eye. Snout convex over surface and in profile, length $1 \frac{1}{6}$ its width. Lower eye but slightly advanced from upper, hind edge about first twofifths in head. Maxillary very oblique, reaches opposite hind pupil edge; expansion $1 \frac{1}{2}$ in lower eye. Mouth large, gape curved, and lower jaw well protruded. Row of strong conic teeth in each jaw, several anteriorly largest and little canine like; no teeth on mouth roof. Front (left) nostril at last two-fifths in snout; hind one well separated, opposite front eye edge. Interorbital narrow, width half upper eye diameter.

Gill-opening forward about opposite hind pupil edge. Gill-rakers $3+15$, lanceolate, $1 \frac{1}{4}$ in filaments, which are $1 \frac{1}{4}$ in eye. Pseudobranchiae two-thirds of gill-filaments.

Scales in rather even longitudinal rows. Dorsal, anal, pectoral and ventral scaleless, and caudal largely covered with small scales. Head, except jaws and snout, scaly. Cheek with 14 rows of scales from lower eye edge to angle of preopercle ridge. Maxillary scaly. Scales cycloid; basal radiating striae 24 or 25 on left or colored side, and 20 or 21 on blind side; lateral line begins below lower eye, then curves upward and back to shoulder on head; arch $3 \frac{2}{5}$ in straight section; moderate tubes simple.

Dorsal begins on snout, opposite front of lower eye. Anal begins opposite pectoral origin. Caudal with median rays longest, forming median obtuse point behind. Pectoral small, pointed. Ventral inserted about opposite hind preopercle edge.

Color in alcohol mummy-brown on left side, and fins similar. Right side paler to olive-gray.

Length $202 \mathrm{~mm}$.

Type.-Cat. No. 83404, U.S.N.M., Rio Janeiro. Wilkes Exploring Expedition.

Also Cat. No. 83399, U.S.N.M. No locality, though doubtless from Rio Janeiro. Wilkes Exploring Expedition. It shows: Head $3 \frac{3}{5}$; depth $1 \frac{1}{2}$; D. 76 ; A. 54 ; scales 102 in lateral line to caudal base; about 95 tubes in lateral line to caudal base; 32 scales above lateral 
line, 35 below; snout $4 \frac{3}{4}$ in head from upper jaw tip; upper eye $4 \frac{1}{2}$; maxillary 2. Gill-rakers $4+14$. Scales with 18 basal striae. Length $148 \mathrm{~mm}$.

This species differs from $X$. notatus (Berg) in its fewer anal rays, finer scales, larger head, maxillary reaching hind pupil edge, and more gill-rakers. According to Ribeiro the A. 64 to 67 , scales 82 to 86 , head 4, gill-rakers $6+11$.

(For Alipo de Miranda Ribeiro, author of Fauna Brasiliense, which we have found of great value in our studies of the Brazilian fishes obtained by the United States Exploring Expedition.) 


\section{$2 \mathrm{BHL}$ Biodiversity Heritage Library}

Fowler, Henry W. and Bean, Barton A. 1923. "Descriptions of eighteen new species of fish from the Wilkes Exploring Expedition, preserved at the United States National Museum." Proceedings of the United States National Museum 63, 1-27. https://doi.org/10.5479/si.00963801.63-2488.1.

View This Item Online: https://www.biodiversitylibrary.org/item/32760

DOI: https://doi.org/10.5479/si.00963801.63-2488.1

Permalink: https://www.biodiversitylibrary.org/partpdf/26465

\section{Holding Institution}

Smithsonian Libraries

\section{Sponsored by}

Smithsonian

\section{Copyright \& Reuse}

Copyright Status: NOT_IN_COPYRIGHT

Rights: https://www.biodiversitylibrary.org/permissions/

This document was created from content at the Biodiversity Heritage Library, the world's largest open access digital library for biodiversity literature and archives. Visit BHL at https://www.biodiversitylibrary.org. 